\title{
Cornelian cherry extract ameliorates osteoporosis associated with hypercholesterolemia in New Zealand rabbits
}

\author{
Beata Nowak ${ }^{1, A-F}$, Agnieszka Matuszewska, ${ }^{1, A-F}$, Magadalena Tomanik $2, B, C, E, F$, Jarosław Filipiak, ${ }^{3, B, C, E, F}$, \\ Alicja Zofia Kucharska ${ }^{4, B, F}$, Narcyz Piórecki, ${ }^{5, F}$, , Diana Jędrzejuk ${ }^{6, C, F}$, Krzysztof Zduniak $^{7, B, C, E, F}$, \\ Małgorzata Trocha ${ }^{1, C, F}$, Marek Bolanowski ${ }^{6, E, F}$, Adam Szeląg ${ }^{1, E, F}$, Tomasz Sozański ${ }^{1, A, B, E, F}$ \\ 1 Department of Pharmacology, Wroclaw Medical University, Poland \\ ${ }^{2}$ Student's Scientific Club, Faculty of Mechanical Engineering, Wroclaw University of Science and Technology, Poland \\ ${ }^{3}$ Faculty of Mechanical Engineering, Wroclaw University of Science and Technology, Poland \\ ${ }^{4}$ Department of Fruit, Vegetable and Plant Nutraceutical Technology, Wroclaw University of Environmental and Life Sciences, Poland \\ ${ }^{5}$ Arboretum Bolestraszyce and Institute of Physiography, University of Rzeszow, Poland \\ ${ }^{6}$ Department of Endocrinology, Diabetes and Isotope Therapy, Wroclaw Medical University, Poland \\ ${ }^{7}$ Department of Pathology, Wroclaw Medical University, Poland \\ A - research concept and design; B - collection and/or assembly of data; $C$ - data analysis and interpretation; \\ $\mathrm{D}$ - writing the article; $\mathrm{E}$ - critical revision of the article; $\mathrm{F}$ - final approval of the article
}

\section{Address for correspondence \\ Beata Nowak}

E-mail: beata.nowak@umed.wroc.pl

\section{Funding sources}

This work was supported by Wroclaw Medical University, Poland (grant No. ST A080.17.035) and by National Science Centre, Poland (grant No. 2016/21/B/NZ7/02759).

Conflict of interest

None declared

Received on March 27, 2020

Review on June 15,2020

Accepted on September 20, 2020

\section{Cite as}

Nowak B, Matuszewska A, Tomanik M, et al. Cornelian cherry extract ameliorates osteoporosis associated with hypercholesterolemia in New Zealand rabbits. Adv Clin Exp Med. 2020;29(12):1389-1397. doi:10.17219/acem/127683

DOI

$10.17219 /$ acem/127683

Copyright

Copyright by Author(s)

This is an article distributed under the terms of the

Creative Commons Attribution 3.0 Unported (CC BY 3.0)

(https://creativecommons.org/licenses/by/3.0/)

\begin{abstract}
Background. Results of animal studies show that a high-cholesterol diet increases bone resorption and decreases bone formation, thus leading to osteoporosis. Previously, we reported on the beneficial influence of Cornelian cherry (Cornus mas L.) fruit on lipid profile in an animal model of diet-induced hipercholesterolemia.
\end{abstract}

Objectives. To investigate the influence of Cornus mas L. extract and loganic acid (LA) on cholesterolinduced bone changes.

Material and methods. The study was conducted on 50 New Zealand rabbits. The animals were given either standard chow (group P) or the same standard chow enriched with 1\% cholesterol (other groups). Additionally, the group CHOL+EX received Cornus mas L. extract, group CHOL+LA - loganic acid, and group CHOL+SIM - simvastatin. Serum concentration of bone turnover markers, bone mineral density (BMD) and bone micro-computed tomography (microCT) were assessed.

Results. In the CHOL group, a decrease in osteocalcin $(\mathrm{OC})$ and an increase in C-terminated telopeptide of type I collagen (CTX) levels were detected (CHOL vs P $0.674 \pm 0.159 \mathrm{ng} / \mathrm{mL}$ vs $1.003 \pm 0.297 \mathrm{ng} / \mathrm{mL}$ and $10.049 \pm 1.276 \mathrm{ng} / \mathrm{mL}$ vs $7.721 \pm 1.187 \mathrm{ng} / \mathrm{mL}$, respectively). The EX and LA ameliorated cholesterolinduced changes in serum OC $(0.857 \pm 0.160 \mathrm{ng} / \mathrm{mL}$ and $1.103 \pm 0.356 \mathrm{ng} / \mathrm{mL}$, respectively) and CTX $(7.735 \pm 1.045 \mathrm{ng} / \mathrm{mL}$ and $8.128 \pm 1.106 \mathrm{ng} / \mathrm{mL}$, respectively). There was a significant decrease in femoral BMD in CHOL group $\left(0.429 \pm 0.11 \mathrm{~g} / \mathrm{cm}^{2}\right.$ vs $\left.0.449 \pm 0.020 \mathrm{~g} / \mathrm{cm}^{2}\right)$. The EX and LA ameliorated those changes $\left(0.458 \pm 0.016 \mathrm{~g} / \mathrm{cm}^{2}\right.$ and $0.449 \pm 0.021 \mathrm{~g} / \mathrm{cm}^{2}$, respectively). The microCT revealed increased bone volume ratio (BV/TV) and trabecular thickness (Tb.Th.) in the CHOL+EX group.

Conclusions. Cornus mas L. inhibited bone resorption and stimulated bone formation, thereby preventing the development of cholesterol-induced osteoporosis.

Key words: osteoporosis, cholesterol, bone mineral density, bone micro-computed tomography, Cornus mas L. 


\section{Introduction}

Osteoporosis is a prevalent systemic bone disease characterized by loss of bone mass and deterioration of its microstructure. Reduced bone mass and disturbances in bone architecture associated with osteoporosis lead to increased risk of fragility fractures representing the main clinical consequence of osteoporosis. Fragility fractures are associated with significant pain and suffering of patients; they lead to disability and even increase the risk of premature death. Hip fragility fracture is the most common reason for elderly people to undergo emergency surgery, and up to $1 / 3$ of those patients die within a year after the osteoporotic fracture. ${ }^{1}$ Osteoporosis is associated with significant physical, psychosocial and financial consequences, and it is becoming a growing public health problem. In 2010 in the EU, 27.5 million people were estimated to have osteoporosis and 3.5 million new fragility fractures were diagnosed. ${ }^{2}$

As bone loss occurs with advancing age, the prevalence of the osteoporosis increases with age. Apart from aging and postmenopausal estrogen deficiency in female, there are many other factors that may accelerate or even induce osteoporosis development. Various drugs (e.g., corticosteroids, systemic antiviral, antacids, antiepileptics, and antithrombotic drugs) ${ }^{3-5}$ and chronic diseases (e.g., diabetes mellitus, hyperthyroidism, hypercortisolemia, hypogonadism, chronic inflammatory diseases, malabsorption etc. $)^{6}$ may influence bone metabolism and lead to excessive loss of bone mass. In recent years, the link between lipid levels and osteoporosis has been described. Many observational studies investigated the association between dyslipidemia, cardiovascular disease and bone mineral density (BMD) ${ }^{7-9}$ Cardiovascular disease and osteoporosis seriously affect quality of life and mortality of middle-aged and elderly people and there is growing evidence that they may share common pathological mechanisms other than age. ${ }^{10}$ Zhang et al. found the significant correlation between BMD and arterial stiffness. ${ }^{11}$ The inverse relationship between BMD and serum total cholesterol and low-density lipoprotein (LDL) level in postmenopausal women was described. ${ }^{12}$ The association between serum triglyceride level and the risk of osteoporotic fractures has also been reported. ${ }^{13}$ The analysis by Lian et al. suggests that serum LDL and total cholesterol levels are major risk factors for senile osteoporosis. ${ }^{10}$ Some evidence suggests that hypercholesterolemia increases the risk of high-turnover osteoporosis. ${ }^{14}$ Results of animal studies show that a high cholesterol diet increases bone resorption and decreases bone formation, thus leading to decreased in BMD in rats. ${ }^{15}$ However, results of studies regarding the effect of lipid-lowering therapies on bone metabolism are ambiguous. ${ }^{16}$

The 2016 American College of Physicians (ACP) guidelines recommend bisphosphonates (alendronate, risedronate, zoledronate) or denosumab in the treatment of osteoporosis in men and women. ${ }^{17}$ Therapy with bisphosphonates and denosumab, although effective, may be associated with various side effects, such as gastrointestinal disturbances, acute phase reaction, nephrotoxicity, atypical fractures, or osteonecrosis of jaw. ${ }^{18}$ Drug toxicity that may necessitate discontinuation of treatment may affect patient compliance. As plants are a rich sources of potentially bioactive substances and many of them have been a part of traditional folk medicine for ages, many researchers focus on herbal drugs that may be useful in osteoporosis therapy. ${ }^{19,20}$

Cornus mas L. (C. mas L.) is a flowering plant cultivated for decorative purposes and as a source of fruits. Cornelian cherry fruit has been studied for various biological properties. There are reports about the beneficial influence of $C$. mas L. fruit on diabetes, different microbial infections, inflammation, and oxidative stress. ${ }^{21}$ Previously, we reported on beneficial influence of C. mas L. fruit on lipid profile in an animal model of diet-induced hypercholesterolemia ${ }^{22}$ and diet-induced atherosclerosis. ${ }^{23-26}$ The beneficial influence of C. mas L. fruit on lipid profile, glycemic indexes and leptin levels was also described by Gholamrezayi et al. ${ }^{27}$ Taking into account the possible common pathogenesis of atherosclerosis and osteoporosis, and our previous results, we decided to investigate the influence of C. mas L. extract (EX) and loganic acid (LA), present in C. mas L. extract, on cholesterol-induced bone changes.

This study was specifically approved by the First Local Ethic Committee for Animal Experiments in Wrocław, Poland (2013 and 2014), and animal experiments were, therefore, performed in accordance with ethical standards laid down in the 1964 Declaration of Helsinki and its later amendments.

\section{Material and methods}

\section{Chemicals and materials}

Acetonitrile for liquid chromatography-mass spectrometry (LC-MS) was purchased from POCH (Gliwice, Poland). Acetonitrile (anhydrous, 99.8\%), formic acid (reagent grade, $\geq 95 \%$ ), acetic acid ( $\geq 99.7 \%$ ), and methanol ( $\geq 99.9 \%)$ were purchased from Sigma-Aldrich (Steinheim, Germany). Loganic acid ( $\geq 99 \%), p$-coumaric acid ( $\geq 90 \%)$, caffeic acid ( $\geq 99 \%$ ), ellagic acid ( $\geq 95 \%$ ), quercetin 3-O-glucoside ( $\geq 98.5 \%)$, kaempferol 3-O-glucoside ( $\geq 99 \%$ ), and cyanidin 3-O-glucoside ( $\geq 90 \%)$ were purchased from Extrasynthese (Lyon, France). Morbital ${ }^{\circledR}$ (1 mL containing $133.3 \mathrm{mg}$ of sodium pentobarbital and $26.7 \mathrm{mg}$ of pentobarbital) was purchased from Biowet Puławy Sp. z o.o. (Poland).

\section{Plant materials and samples preparation of extract and loganic acid}

Cornelian cherry fruits were collected in the Arboretum Bolestraszyce and Institute of Physiography, Bolestraszyce, Poland. The plant material was verified by Jakub Dolatowski and the voucher specimen (BDPA 3967) has been deposited at the Arboretum Herbarium and Institute of Physiography in Bolestraszyce. The investigated extract 
Table 1. Identification and the content (mg/100 g dw) of main compounds of extracts from Cornelian cherry fruits using UPLC-ESI-qTOF-MS/MS and HPLC-PDA

\begin{tabular}{|c|c|c|c|c|c|c|}
\hline $\begin{array}{l}\text { Peak } \\
\text { No. }\end{array}$ & $t_{R}[\mathrm{~min}]$ & Compound & $\begin{array}{l}\mathrm{UV} \lambda_{\max } \\
{[\mathrm{nm}]}\end{array}$ & $\begin{array}{c}{[\mathrm{M}-\mathrm{H}]^{-} /[\mathrm{M}+\mathrm{H}]^{+}} \\
{[\mathrm{m} / \mathrm{z}]}\end{array}$ & $\begin{array}{c}\text { Other ions } \\
{[\mathrm{m} / \mathrm{z}]}\end{array}$ & $\begin{array}{c}\text { Content } \\
{[\mathrm{mg} / 100 \mathrm{~g} \mathrm{dw}]}\end{array}$ \\
\hline \multicolumn{7}{|c|}{ Iridoids } \\
\hline 1 & 4.9 & loganic acid & 246 & $375(377+)$ & $213(215+)$ & $10870.20 \pm 15.86$ \\
\hline 2 & 16.1 & cornuside & $245 / 273$ & $541(543+)$ & $169(171+)$ & $1549.28 \pm 3.43$ \\
\hline \multicolumn{6}{|c|}{ total } & 12419.48 \\
\hline \multicolumn{7}{|c|}{ Anthocyanins } \\
\hline 3 & 6.3 & delphinidin 3-O-galactoside & 524 & $463+$ & $303+$ & $44.06 \pm 1.77$ \\
\hline 4 & 7.6 & cyanidin 3-O-galactoside; & 515 & $449+$ & $287+$ & $809.70 \pm 0.55$ \\
\hline 5 & 8.3 & cyanidin 3-O-robinobioside & 516 & $595+$ & $287+$ & $369.94 \pm 1.41$ \\
\hline 6 & 8.8 & pelargonidin 3-O-galactoside & 501 & $433+$ & $271+$ & $1542.22 \pm 0.84$ \\
\hline 7 & 9.5 & pelargonidin 3-O-robinobioside & 501 & $579+$ & $271+$ & $297.18 \pm 0.44$ \\
\hline 8 & 12.6 & cyanidin & 523 & $287+$ & - & $222.98 \pm 31.61$ \\
\hline 9 & 15.1 & pelargonidin & 509 & $271+$ & - & $396.55 \pm 67.49$ \\
\hline \multicolumn{6}{|c|}{ total } & 3682.63 \\
\hline \multicolumn{7}{|c|}{ Phenolic acids } \\
\hline 10 & 4.1 & caffeoyl hexoside & 326 & 341 & 179 & $120.28 \pm 3.00$ \\
\hline 11 & 4.6 & p-coumaroilquinic acid 1 & 316 & 337 & 163 & $33.91 \pm 1.40$ \\
\hline 12 & 5.8 & caffeoylquinic acid & 324 & 353 & 191 & $471.45 \pm 1.42$ \\
\hline 13 & 7.9 & p-coumaric acid & 309 & 163 & - & $12.40 \pm 0.21$ \\
\hline 14 & 8.3 & p-coumaroilquinic acid 2 & 313 & 337 & $191 / 163$ & $279.91 \pm 3.50$ \\
\hline 15 & 10.0 & p-coumaroilquinic acid 3 & 312 & 337 & $191 / 163$ & $20.91 \pm 1.88$ \\
\hline 16 & 12.3 & ellagic acid & $254 / 362$ & 301 & - & $124.21 \pm 1.64$ \\
\hline \multicolumn{6}{|c|}{ total } & 1063.07 \\
\hline \multicolumn{7}{|c|}{ Flavonols } \\
\hline 17 & 13.2 & quercetin 3-O-glucuronide & 354 & 477 & 301 & $306.28 \pm 22.62$ \\
\hline 18 & 13.7 & quercetin 3-O-glucoside & 353 & 463 & 301 & $31.64 \pm 1.58$ \\
\hline 19 & 14.8 & kaempferol 3-O-galactoside & 348 & 447 & 285 & $215.45 \pm 2.61$ \\
\hline 20 & 15.6 & kaempferol 3-O-glucuronide & 351 & 461 & 285 & $35.94 \pm 1.38$ \\
\hline \multicolumn{6}{|c|}{ total } & 589.30 \\
\hline
\end{tabular}

(EX) was prepared from C. mas L. fruits by the Department of Fruit, Vegetable and Plant Nutraceutical Technology at Wrocław University of Environmental and Life Sciences according to the method described by Kucharska et al. ${ }^{28}$ and Sozański et al. ${ }^{29}$ The extract of iridoids and phenolic compounds (EX) was obtained after purification on XAD-16 Amberlite resin (Rohm and Haas, Chauny, France) in a column, concentration using a Rotavapor (Unipan, Warszawa, Poland), and lyophilization (Alpha 1-4 LSC; Martin Christ Gefriertrocknungsanlagen $\mathrm{GmbH}$, Osterode am Harz, Germany). ${ }^{28}$ The extract was qualitatively and quantitatively characterized using LC-MS and highperformance liquid chromatography (HPLC) (Table 1).

\section{Identification of compounds by UPLC-ESI-qTOF-MS/MS}

Compounds were identified with the method described by Kucharska at al., ${ }^{30}$ using the Acquity ultra-performance liquid chromatography (UPLC) system coupled with a quadrupole time of flight (q-TOF) MS instrument (Waters Corp., Milford, USA), with an electrospray ionization (ESI) source. Separation was achieved with an Acquity BEH C18 column (100 mm × $2.1 \mathrm{~mm}$ i.d., $1.7 \mu \mathrm{m}$; Waters). The mobile phase was a mixture of $2.0 \%$ aq. formic acid v/v (solvent $\mathrm{A}$ ) and acetonitrile with formic acid (solvent $\mathrm{B}$ ). The instrument was operated both in the positive (iridoids and anthocyanins) and the negative (iridoids, phenolic acids, flavonols, and anthocyanins) ion mode, scanning m/z from 100 to 1500.

\section{Quantification of compounds by HPLC-PDA}

Iridoids and anthocyanins were assayed using the method described by Kucharska et al. ${ }^{30}$ with a Dionex HPLC Ultimate 3000 system (Germering, Germany) equipped with the diode array detector. The Cadenza Imtakt (Portland, USA) column C5-C18 (75 $4.6 \mathrm{~mm}, 5 \mu \mathrm{m})$ was used. The mobile phase was composed of solvents: A (4.5\% aq. formic acid, v/v) and B (acetonitrile with formic acid), 
as described by Kucharska et al. ${ }^{30}$ Runs were monitored at wavelengths of $245 \mathrm{~nm}$ (iridoids), $254 \mathrm{~nm}$ (ellagic acid), $320 \mathrm{~nm}$ (phenolic acids), $360 \mathrm{~nm}$ (flavonols), and $520 \mathrm{~nm}$ (anthocyanins). Peaks corresponding to standards were quantified, and iridoid was quantified as LA, anthocyanins as cyanidin 3-O-glucoside, phenolic acid as $p$-coumaric acid, caffeic acid and ellagic acid, and flavonols as quercetin 3-O-glucoside and kaempferol 3-O-glucoside.

\section{Animal model and protocol}

The study was conducted on 50 male sexually mature New Zealand rabbits, aged 8-12 months and weighing $4.5-5.5 \mathrm{~kg}$. The animals were housed in individual chambers with temperature maintained at $21-23^{\circ} \mathrm{C}$ on a regular $12 \mathrm{~h}$ light/dark cycle. During the experiment the animals had water ad libitum and received the same daily portion of chow $(40 \mathrm{~g} / \mathrm{kg})$. The animals were acclimated for 3 weeks prior to being used in the sixty-day study. After acclimatization, the animals were randomly divided into 5 groups (NT, CHOL, CHOL+EX, CHOL+LA, and CHOL+SIM) of 10 animals each. For 60 consecutive days of the experiment, the animals were given either standard chow (group NT) or the same standard chow enriched with 1\% cholesterol (groups CHOL, CHOL+EX, CHOL+LA, and $\mathrm{CHOL}+\mathrm{SIM}$ ). Once daily, in the morning, the following test substances were administered orally to the rabbits: group $\mathrm{NT}$ and $\mathrm{CHOL}$ - normal saline solution, group $\mathrm{CHOL}+\mathrm{EX}$ - C. mas L. extract, group CHOL+LA - loganic acid, and group $\mathrm{CHOL}+\mathrm{SIM}$ - simvastatin (Table 2).

On day 60, blood samples were collected from each animal from the margin vein of the ear or the saphenous vein. Serum was separated using centrifugation (at $1500 \times \mathrm{g}$ ) and then stored at $70^{\circ} \mathrm{C}$ until required for bone metabolic marker assays.

On day 60 , the animals were euthanized with terminal anesthesia, using Morbital ${ }^{\circledR}$ (Biowet, Puławy, Poland; $1 \mathrm{~mL}$ containing $133.3 \mathrm{mg}$ of sodium pentobarbital and $26.7 \mathrm{mg}$ of pentobarbital) at a dose of $2 \mathrm{~mL} / \mathrm{kg}$ given intraperitoneally (i.p.). The femur and tibia were cleaned off all soft tissues and carefully separated. Left femurs were fixed in buffered formaldehyde for further histological examination. Right femurs and tibias were frozen and stored at the temperature of $-70^{\circ} \mathrm{C}$ for further examination (dualenergy X-ray absorptiometry (DXA) and micro-computed tomography (microCT).

\section{Measurement of relevant serum parameters}

Serum total calcium and inorganic phosphorus were measured with Architect plus ci4100 (Abbott, Chicago, USA) using commercial tests (Calcium Architect/Aeroset REF 3L79-21 and 3L79-31 304328/R1, Abbott; Phosphorus Architect REF 7D71 305532/R02, Abbott).

Serum osteocalcin (OC) and C-terminated telopeptide of type I collagen (CTX) levels (sensitive biochemical markers of bone formation and bone resorption, respectively) were determined using commercial OC (Rabbit Osteocalcin (OC) ELISA Kit; Wuhan USCN Cloud-Clone Corp, Wuhan, China) and CTX (Rabbit CTXI (Cross Linked C-telopeptide of Type I Collagen) ELISA Kit, Fine Test; Wuhan Fine Biotech Corp, Wuhan, China) enzymelinked immunosorbent assay (ELISA) kits. All ELISA tests were performed according to their manufacturers' instructions.

\section{Determination of bone mineral density}

Bone mineral density of the right femoral bones was measured by trained examiners using DXA with Hologic DXA equipment (Hologic Discovery W 81507; Hologic, Mississauga, Canada) using software for small animals. The results were obtained as grams of mineral content per square centimeter of bone area $\left(\mathrm{g} / \mathrm{cm}^{2}\right)$. The scanner was calibrated daily using a phantom provided by the manufacturer.

\section{MicroCT evaluation of the bone structure}

In order to evaluate the bone structure from each group, 5 randomly selected tibias $(n=25)$ were scanned with high-resolution microCT (SkyScan 1172; Bruker ${ }^{\circledR}$, Billerica, USA). For acquiring the images with 9.0- $\mu \mathrm{m}$ pixel size, the X-ray tube was set at $95 \mathrm{kV}$ and $104 \mu \mathrm{A}$, along with a copper-aluminium $(\mathrm{CuAl})$ filter. For the quantitative evaluation, only the distal part of the tibia was taken under consideration. After the reconstruction process, a set of $2 \mathrm{D}$ cross-sections representing the bone structure of the specimens was obtained.

Prior to the 3D morphometric analyses, the images were aligned with the bone major axis and the set of trabecular and cortical volumes of interests (VOIs) were selected,

Table 2. Experimental groups

\begin{tabular}{|l|c|c|c|}
\multicolumn{1}{c|}{ Group } & Chow & Tested substance \\
\hline $\mathrm{P}$ & standard chow & none \\
\hline $\mathrm{CHOL}$ & standard chow $+1 \%$ cholesterol & none \\
\hline $\mathrm{CHOL}+\mathrm{EX}$ & standard chow $+1 \%$ cholesterol & Cornelian cherry extract & none \\
\hline $\mathrm{CHOL}+\mathrm{LA}$ & standard chow $+1 \%$ cholesterol & loganic acid \\
\hline $\mathrm{CHOL}+\mathrm{SIM}$ & standard chow $+1 \%$ cholesterol & simvastatin & $20 \mathrm{mg} / \mathrm{kg}$ \\
\hline
\end{tabular}

P - placebo; CHOL - cholesterol; EX - C. mas L. extract; LA - loganic acid; SIM - simvastatin. 


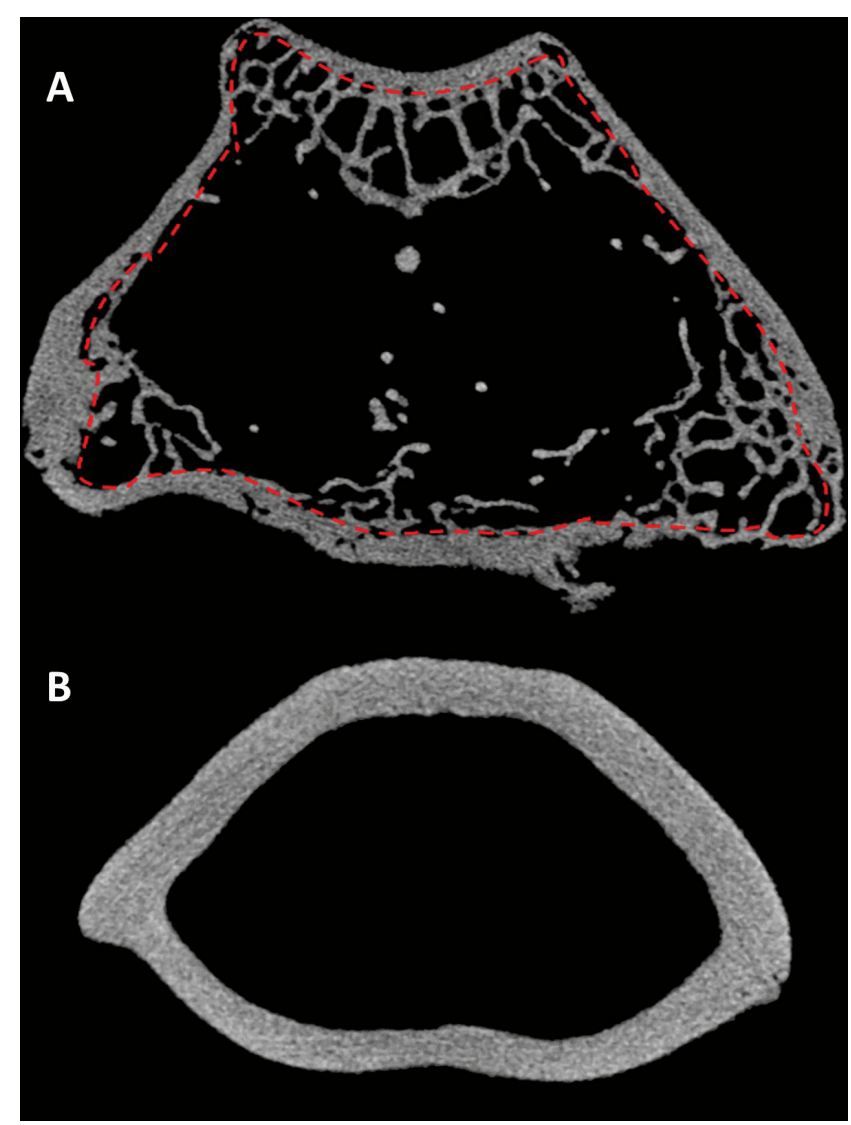

Fig. 1. The representative microCT cross sections of $(A)$ the trabecular region (within the red line) and (B) cortical region

with reference to the growth plate. The selection of both regions of interest (trabecular and cortical) was based on the commonly accepted procedure used for small animals. ${ }^{31,32}$ Within each VOI, the automatic selection of a specific bone (Fig. 1) was applied; then, the images were segmented, using an adaptive global threshold algorithm. Quantitate analysis (CTAnn; Bruker ${ }^{\circledR}$ ) of the cancellous bone structure took into account bone volume ratio (BV/ $\mathrm{TV}$ ), bone surface ratio (BS/BV) trabecular thickness ( $\mathrm{Tb}$. Th), number (Tb.N) and pattern (Tb.Pf), as well as structural model index (SMI). Apart from the basic parameters (BV/TV and BV/BS), the cortical thickness (Cr.Th) was calculated for the cortical bone. Furthermore, to complete the densitometric analysis for the cortical bone datasets, $\mathrm{X}$-ray absorption, defined as the attenuation coefficient $\left(\mathrm{AC}\left[\mathrm{mm}^{-1}\right]\right)$ determining both by mass density and elemental composition of the material, was calculated.

\section{Thickness of femoral cortical bone}

Left femoral bones were fixed in $10 \%$ neutral-buffered formaldehyde and were then decalcified in 5\% formic acid and $5.6 \%$ hydrochloric acid solution for 14 days. Next, the bones were embedded in paraffin and fixed, and 4- $\mu \mathrm{m}$ histological sections, stained with hematoxylin and eosin (H\&E), were subsequently prepared. Histological slides were scanned with the NanoZoomer v. 2.0 (Hamamatsu Photonics K.K., Hamamatsu, Japan). The thickness of the cortical bone was measured $40 \mathrm{~mm}$ from the distal metaphysis of the femur.

\section{Statistical analysis}

Parametric data was expressed as means \pm standard deviation (SD). The statistical analysis was carried out using STATISTICA v. 13 (StatSoft, Inc., Tulsa, USA). The normality of all continuous variables was verified with the Shapiro-Wilk test. One-way analysis of variance (ANOVA) with least significant difference (LSD) Fisher's post hoc test was performed for a comparison involving 3 or more groups. The limit of significance was set at $\mathrm{p}<0.05$.

\section{Results}

\section{Serum concentration of bone turnover markers}

Serum total calcium and inorganic phosphorus levels, and serum concentration of OC and CTX are presented in Table 3. A decrease in serum calcium was detected in animals fed with a cholesterol-reach diet and receiving C. mas L. deviates or simvastatin. Inorganic phosphorus levels were increased only in animals fed with a cholesterol-reach diet and receiving $C$. mas L. deviates. C. mas L. extract and LA ameliorated cholesterol-induced

Table 3. Selected serum parameters measured on day 60

\begin{tabular}{|c|c|c|c|c|c|}
\hline \multirow[b]{2}{*}{ Parameter [unit] } & \multicolumn{5}{|c|}{ Experimental groups } \\
\hline & $\begin{array}{c}P \\
(n=10)\end{array}$ & $\begin{array}{l}\mathrm{CHOL} \\
(n=10)\end{array}$ & $\begin{array}{l}\mathrm{CHOL}+\mathrm{EX} \\
(\mathrm{n}=10)\end{array}$ & $\begin{array}{l}\mathrm{CHOL}+\mathrm{LA} \\
(\mathrm{n}=10)\end{array}$ & $\begin{array}{l}\mathrm{CHOL}+\mathrm{SIM} \\
(\mathrm{n}=10)\end{array}$ \\
\hline Total calcium [mmol/L] & $3.547 \pm 0.193$ & $3.394 \pm 0.148$ & $3.283 \pm 0.224^{* *}$ & $3.380 \pm 0.126^{*}$ & $3.348 \pm 0.152^{*}$ \\
\hline $\begin{array}{l}\text { Inorganic phosphorus } \\
{[\mathrm{mmol} / \mathrm{L}]}\end{array}$ & $1.489 \pm 0.183$ & $1.935 \pm 0.569$ & 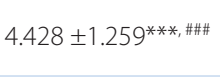 & $2.731 \pm 1.210^{\# \#}$ & $1.452 \pm 0.201$ \\
\hline $\mathrm{OC}[\mathrm{ng} / \mathrm{mL}]$ & $1.003 \pm 0.297^{* *}$ & $0.674 \pm 0.159^{\# \#}$ & $0.857 \pm 0.160$ & $1.103 \pm 0.356^{*}$ & $0.722 \pm 0.190^{\#}$ \\
\hline CTX [ng/mL] & $7.721 \pm 1.187^{* * *}$ & $10.049 \pm 1.276^{\# \# \#}$ & $7.735 \pm 1.045^{* * *}$ & $8.128 \pm 1.106^{* * *}$ & $7.252 \pm 1.064^{* * *}$ \\
\hline
\end{tabular}

P - placebo; OC - osteocalcin; CTX - C-terminated telopeptide of type I collagen; * $p<0.05 ;{ }^{* *} p<0.01$; ** $p<0.001$ compared to CHOL; ${ }^{*} p<0.05$;

\#\# $\mathrm{p} 0.01 ; \# \mathrm{p}<0.001$ compared to $\mathrm{P}$. 
decrease in OC concentration, whereas in the simvastatin group OC level remained lower than in the placebo group. We observed normalization of cholesterol-induced increase in CTX level in animals receiving C. mas L. extract, LA and simvastatin.

\section{Bone mineral density}

Femoral BMD is presented in Fig. 2. There is a significant decrease in femoral BMD in the CHOL group in comparison to the not-treated (NT) one $\left(0.429 \pm 0.11 \mathrm{~g} / \mathrm{cm}^{2}\right.$ vs $\left.0.449 \pm 0.020 \mathrm{~g} / \mathrm{cm}^{2}, \mathrm{p}=0.033\right)$. The $C$. mas $\mathrm{L}$. extract and LA ameliorate cholesterol-induced changes in BMD $\left(0.458 \pm 0.016 \mathrm{~g} / \mathrm{cm}^{2}, \mathrm{p}=0.004\right.$ and $0.449 \pm 0.021 \mathrm{~g} / \mathrm{cm}^{2}$, $\mathrm{p}=0.039$, respectively). There was no difference between CHOL and CHOL+SIM group $\left(0.422 \pm 0.021 \mathrm{~g} / \mathrm{cm}^{2}\right)$.

\section{Histopathological examination}

A histopathological examination revealed no significant difference in the thickness of the femoral cortical bone between groups (NT: $0.910 \pm 0.056 \mathrm{~mm}, \mathrm{CHOL}$ : $0.872 \pm 0.092 \mathrm{~mm}, \mathrm{CHOL}+\mathrm{EX}: 0.895 \pm 0.055 \mathrm{~mm}, \mathrm{CHOL}+\mathrm{LA}$ : $0.887 \pm 0.076$ and CHOL+SIM: $0.878 \pm 0.086 \mathrm{~mm}$ ).

\section{MicroCT morphometry}

Microstructural cancellous and cortical bone parameters are presented in Table 4, and examples of crosssections in 3 orthogonal planes are shown in Fig. 3. In the CHOL-EX group, the bone volume ratio was $29 \%$ higher than in the CHOL group. Such an increase was not detected in the CHOL+SIM group. Apart from this, bone trabeculae were $14 \%$ thicker in the $\mathrm{CHOL}+\mathrm{EX}$ group than in animals receiving simvastatin. We detected no influence of investigated substances on cortical bone.

\section{Discussion}

Osteoporosis is characterized by the imbalance between osteoblast and osteoclast activity, leading to bone loss and disturbances in its microarchitecture. Hypercholesterolemia seems to be a possible triggering factor that may affect homeostasis between bone formation and bone resorption, thus leading to osteoporosis. You et al. reported increased serum CTX level with decreased serum OC level in rats fed with cholesterol-rich diet. ${ }^{15}$ In cholesterol-fed rats, they observed inhibition of proliferation and differentiation of osteoblasts and decreased BMP2 (bone morphogenic protein 2) expression, leading to decreased bone formation. In the conducted study, we also noticed an increase in serum CTX level and a decrease in serum OC level in animals fed with cholesterol-rich diet, which is a sign of increased bone resorption and decreased bone formation. In our study, changes in concentrations of bone turnover markers were associated with decreased femoral BMD, as reported by You et al. ${ }^{15}$ These changes are similar to those observed in postmenopausal osteoporosis and in ovariectomy-induced osteoporosis in animal models. ${ }^{33,34}$ The C. mas L. extract (50 mg/kg), LA (20 mg/kg) and simvastatin ( $5 \mathrm{mg} / \mathrm{kg})$ given simultaneously with cholesterol-rich diet prevented the increase in CTX level, which is evidence of their antiresorptive activity. In the $\mathrm{CHOL}+\mathrm{EX}$ and $\mathrm{CHOL}+\mathrm{LA}$ group, we detected no decrease in OC levels, which suggest that they may stimulate bone formation. The beneficial effect
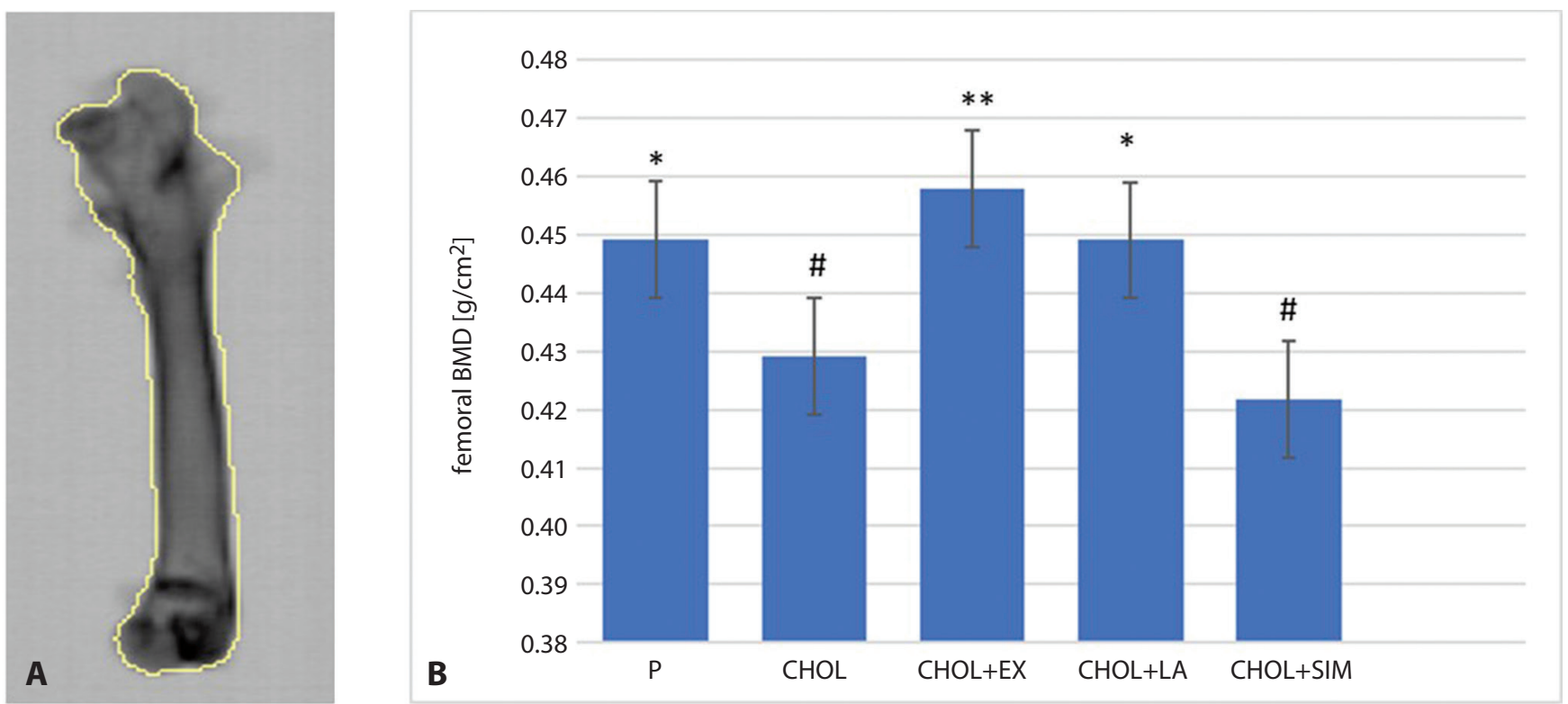

Fig. 2. Femoral BMD examination

A - DXA scan of right femur; B - femoral BMD in experimental groups ( $\mathrm{P}$ - placebo; $\mathrm{CHOL}-1 \%$ cholesterol; $\mathrm{CHOL}+\mathrm{EX}-1 \%$ cholesterol + Cornelian cherry extract $50 \mathrm{mg} / \mathrm{kg} ; \mathrm{CHOL}+\mathrm{LA}-1 \%$ cholesterol + LA $20 \mathrm{mg} / \mathrm{kg} ; \mathrm{CHOL}+\mathrm{SIM}-1 \%$ cholesterol $+\operatorname{simvastatin} 5 \mathrm{mg} / \mathrm{kg}) ;{ }^{*} \mathrm{P}<0.05 ;{ }^{* *} \mathrm{P}<0.01 \mathrm{vs} \mathrm{CHOL} ;{ }^{\#} \mathrm{P}<0.05 \mathrm{vs} \mathrm{P}$. 
Table 4. Microstructural parameters obtained for cancellous and cortical bone of distal tibia metaphysis, microCT evaluation. Results presented as: mean \pm SD. Experimental groups: $\mathrm{P}$ - placebo, CHOL - 1\% cholesterol, CHOL+EX - 1\% cholesterol + Cornelian cherry extract 50 mg/kg, $\mathrm{CHOL}+\mathrm{LA}-1 \%$ cholesterol + loganic acid $20 \mathrm{mg} / \mathrm{kg}, \mathrm{CHOL}+\mathrm{SIM}-1 \%$ cholesterol + simvastatin $5 \mathrm{mg} / \mathrm{kg}$

\begin{tabular}{|c|c|c|c|c|c|}
\hline \multirow[b]{2}{*}{ Parameter [units] } & \multicolumn{5}{|c|}{ Experimental groups } \\
\hline & $\begin{array}{c}P \\
(n=5)\end{array}$ & $\begin{array}{l}\text { CHOL } \\
(n=5)\end{array}$ & $\begin{array}{c}\mathrm{CHOL}+\mathrm{EX} \\
(n=5)\end{array}$ & $\begin{array}{c}\mathrm{CHOL}+\mathrm{LA} \\
(\mathrm{n}=5)\end{array}$ & $\begin{array}{c}\mathrm{CHOL}+\mathrm{SIM} \\
(n=5)\end{array}$ \\
\hline \multicolumn{6}{|c|}{ Cancellous bone } \\
\hline $\mathrm{BV} / \mathrm{TV}[\%]$ & $9.53 \pm 0.72$ & $9.37 \pm 1.94$ & $12.11 \pm 3.30^{\# *^{\circ}}$ & $10.11 \pm 2.18$ & $9.09 \pm 3.81$ \\
\hline $\mathrm{BS} / \mathrm{BV}[1 / \mathrm{U}]$ & $25.11 \pm 2.55^{\circ}$ & $24.51 \pm 1.99^{\circ \circ}$ & $23.55 \pm 1.26^{\circ 00}$ & $23.59 \pm 1.45^{\circ 00}$ & $27.28 \pm 2.31^{\#, * *}$ \\
\hline Tb.Th. [mm] & $0.162 \pm 0.021$ & $0.157 \pm 0.014$ & $0.173 \pm 0.014^{\circ}$ & $0.166 \pm 0.013$ & $0.152 \pm 0.007$ \\
\hline Tb.N. [1/mm] & $0.594 \pm 0.073$ & $0.600 \pm 0.137$ & $0.708 \pm 0.222$ & $0.609 \pm 0.118$ & $0.597 \pm 0.219$ \\
\hline Tb.Pf. [ratio] & $7.611 \pm 1.277$ & $6.858 \pm 1.255^{\circ \circ}$ & $7.525 \pm 0.852$ & $6.775 \pm 0.599^{\circ \circ}$ & $8.634 \pm 1.777^{* *}$ \\
\hline SMI [1] & $1.812 \pm 0.190$ & $1.680 \pm 0.273$ & $1.922 \pm 0.244$ & $1.726 \pm 0.160$ & $1.900 \pm 0.274$ \\
\hline \multicolumn{6}{|c|}{ Cortical bone } \\
\hline $\mathrm{BV} / \mathrm{TV}[\%]$ & $34.77 \pm 1.97$ & $34.10 \pm 5.49$ & $37.58 \pm 2.57$ & $36.01 \pm 2.38$ & $33.92 \pm 4.39$ \\
\hline $\mathrm{BS} / \mathrm{BV}[1 / \mathrm{U}]$ & $3.88 \pm 0.22$ & $4.17 \pm 0.98$ & $4.15 \pm 1.04$ & $3.89 \pm 0.39$ & $4.44 \pm 0.84$ \\
\hline Cr.Th. $[\mathrm{mm}]$ & $0.837 \pm 0.048$ & $0.825 \pm 0.137$ & $0.831 \pm 0.144$ & $0.855 \pm 0.058$ & $0.763 \pm 0.087$ \\
\hline $\mathrm{AC}[1 / \mathrm{mm}]$ & $0.0253 \pm 0.0012$ & $0.0256 \pm 0.0011$ & $0.0267 \pm 0.0011$ & $0.0266 \pm 0.0007$ & $0.0268 \pm 0.0013^{\#}$ \\
\hline
\end{tabular}

micoCT - micro-computed tomography; P - placebo; BV/TV - bone volume ratio; BS/BV - bone surface ratio; Tb.Th. - trabecular thickness; Tb.N. - trabecular number; Tb.Pf. - trabecular pattern; SMI - structural model index; Cr.Th. - cortical thickness; AC - attenuation coefficient; ${ }^{*} \mathrm{p}<0.05 ;{ }^{* *} \mathrm{p}<0.01$ compared to $\mathrm{CHOL} ;{ }^{*} \mathrm{p}<0.05$ compared to $\mathrm{P} ;{ }^{\circ} \mathrm{p}<0.05 ;^{\circ 0} \mathrm{p}<0.01 ;{ }^{\circ 00} \mathrm{p}<0.001$ compared to $\mathrm{CHOL}+\mathrm{SIM}$.
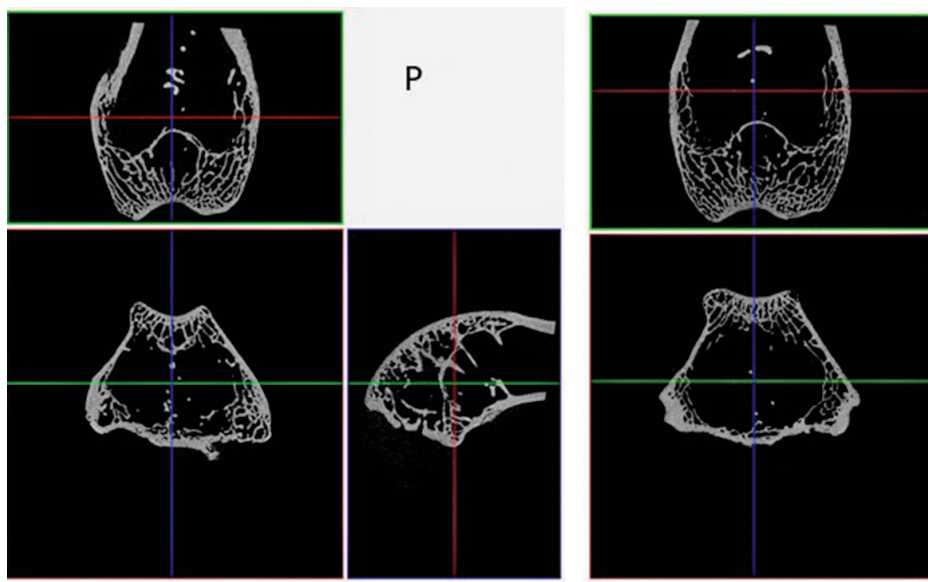

$\mathrm{CHOL}$
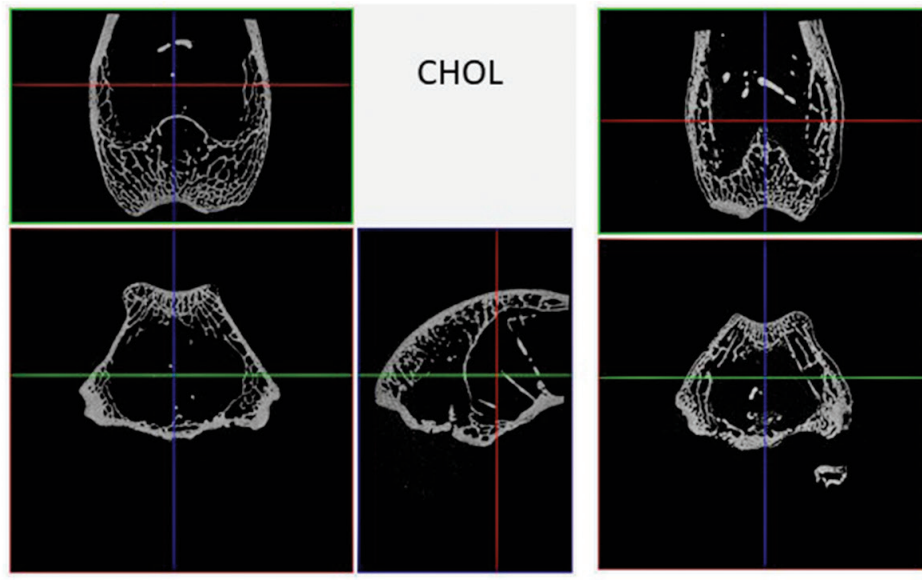

$\mathrm{CHOL}+\mathrm{EX}$
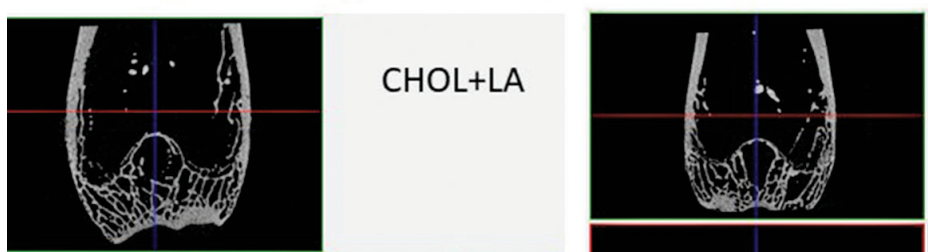

$\mathrm{CHOL}+\mathrm{SIM}$
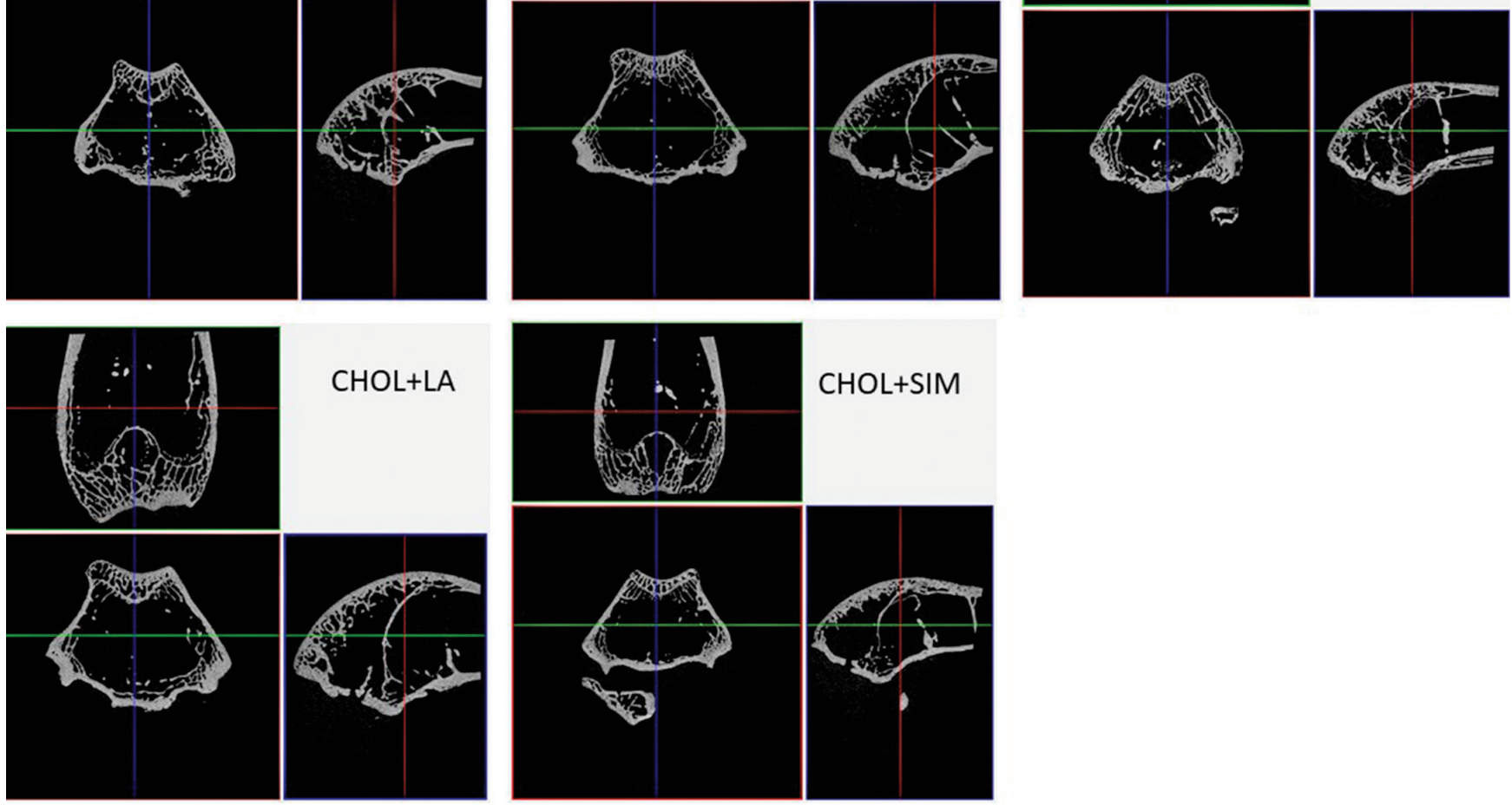

Fig. 3. MicroCT scans of tibias in experimental groups

P - placebo; $\mathrm{CHOL}$ - 1\% cholesterol; CHOL+EX - 1\% cholesterol + Cornelian cherry extract 50 mg/kg; CHOL+LA - 1\% cholesterol + LA 20 mg/kg; $\mathrm{CHOL}+\mathrm{SIM}-1 \%$ cholesterol + simvastatin $5 \mathrm{mg} / \mathrm{kg}$ 
of simvastatin on bone metabolism was described by some authors. Simvastatin local delivery and high systemic doses had a beneficial effect on fractures healing. ${ }^{35}$ Simvastatin was reported to alleviate bone resorption and bone loss. ${ }^{36,37}$ Some authors also described its beneficial effect on bone formation, ${ }^{38}$ but we did not observe such an effect in our study.

The difference in the calcium level between the CHOL group and the animals receiving additionally Cornelian cherry derivatives or simvastatin may be attributed to the antiresorptive properties of Cornelian cherry extract, LA and simvastatin. The inhibition of bone resorption decreases the mobilization of calcium from bone tissue, and as a consequence lower serum calcium level is observed. The increased level of inorganic phosphorus in the $\mathrm{CHOL}+\mathrm{EX}$ and $\mathrm{CHOL}+\mathrm{LA}$ groups needs further explanation.

In $\mathrm{CHOL}+\mathrm{EX}$ and $\mathrm{CHOL}+\mathrm{LA}$ groups, we did not observe cholesterol-induced bone loss. Simvastatin did not exert a protective effect on femoral BMD. Shahrezaee et al. reported an increase in BMD in ovariectomized rats treated with simvastatin. ${ }^{39}$ However, the discrepancy with our study may be a consequence of the fact that Shahrezaee et al. investigated higher doses of simvastatin $(25 \mathrm{mg} / \mathrm{kg})$ and used a different animal model. Shahrezaee et al. investigated the influence of simvastatin on estrogen-deficiency-induced osteoporosis and they used a classical animal model for such a condition. However, ovariectomy does not induce lipid changes in rats, so it does not allow us to predict the influence of simvastatin on cholesterol-induced bone changes. As we planned to concentrate on atherosclerosis-associated bone changes, we used cholesterol-fed rabbit model, which is a standard model used in animal studies on atherosclerosis. ${ }^{40}$ In the $\mathrm{CHOL}+\mathrm{EX}$ group, femoral BMD was even higher than in the placebo group, which supports the hypothesis that Cornelian cherry extract may induce new bone formation. Cornus mas L. extract seems to have a beneficial influence on cancellous bone, as in the $\mathrm{CHOL}+\mathrm{EX}$ group we found an increase in bone volume ratio (BV/TV). Apart from that, the trabeculae were thicker in animals receiving Cornelian cherry extract than in rabbits receiving simvastatin.

As Cornelian cheery extract exerted effects that were not observed in simvastatin-treated animals, we suspect that these effects may not be limited to its lipid lowering properties.

\section{Conclusions}

To our knowledge, this is the first in vivo study investigating the influence of C. mas $\mathrm{L}$. on the disturbances of bone metabolism and structure. Our study revealed the beneficial influence of C. mas L. and LA on cholesterolinduced osteopenia in rabbits. However, further research is needed to establish the mechanism of the observed effects, and to investigate the influence of Cornelian cherry on other forms of osteoporosis.

\section{ORCID iDs}

Beata Nowak (1) https://orcid.org/0000-0003-0014-6344 Agnieszka Matuszewska (1) https://orcid.org/0000-0003-1082-0793 Magadalena Tomanik (1) https://orcid.org/0000-0002-7249-6266 Jarosław Filipiak (1) https://orcid.org/0000-0002-9380-0642 Alicja Zofia Kucharska (1) https://orcid.org/0000-0002-2172-0408 Narcyz Piórecki (i) https://orcid.org/0000-0002-0256-5510 Diana Jędrzejuk (10) https://orcid.org/0000-0001-7053-142X Krzysztof Zduniak (1) https://orcid.org/0000-0003-4652-4478 Małgorzata Trocha (1) https://orcid.org/0000-0002-3951-205X Marek Bolanowski (D) https://orcid.org/0000-0002-2360-6596

Adam Szeląg (i) https://orcid.org/0000-0001-8104-5267

Tomasz Sozański (i) https://orcid.org/0000-0003-1722-3190

\section{References}

1. Johansen A, Tsang C, Boulton C, Wakeman R, Moppett I. Understanding mortality rates after hip fracture repair using ASA physical status in the National Hip Fracture Database. Anaesthesia. 2017;72(8):961-966. doi:10.1111/anae.13908

2. Hernlund E, Svedbom A, Ivergård M, et al. Osteoporosis in the European Union: Medical management, epidemiology and economic burden. Arch Osteoporos. 2013;8(1-2):136. doi:10.1007/s11657-013-0136-1

3. Panday K, Gona A, Humphrey MB. Medication-induced osteoporosis: Screening and treatment strategies. Ther Adv Musculoskelet Dis. 2014;6(5):185-202. doi:10.1177/1759720X14546350

4. Matuszewska A, Nowak B, Rzeszutko M, et al. Effects of long-term administration of pantoprazole on bone mineral density in young male rats. Pharmacol Reports. 2016 68(5):1060-1064. doi:10.1016/j. pharep.2016.06.012

5. Nowak B, Matuszewska A, Filipiak J, et al. The influence of bexarotene, a selective agonist of the retinoid receptor X (RXR), and tazarotene, a selective agonist of the retinoid acid receptor (RAR), on bone metabolism in rats. AdvMed Sci.2016;61(1):85-89. doi:10.1016/j.advms.2015.09.001

6. Sheu A, Diamond T. Secondary osteoporosis. Aust Prescr. 2016;39(3): 85-87. doi:10.18773/austprescr.2016.038

7. Bagger YZ, Rasmussen HB, Alexandersen P, et al. Links between cardiovascular disease and osteoporosis in postmenopausal women: Serum lipids or atherosclerosis per se? Osteoporos Int. 2007;18(4):505-512. doi:10.1007/s00198-006-0255-2

8. Ackert-Bicknell CL. HDL cholesterol and bone mineral density: Is there a genetic link? Bone. 2012;50(2):525-533. doi:10.1016/j.bone.2011.07.002

9. Hu X, Ma S, Yang C, Wang W, Chen L. Relationship between senile osteoporosis and cardiovascular and cerebrovascular diseases. Exp Ther Med. 2019;17(6):4417-4420. doi:10.3892/etm.2019.7518

10. Lian XL, Zhang YP, Li X, Jing LD, Cairang ZM, Gou JQ. Exploration on the relationship between the elderly osteoporosis and cardiovascular disease risk factors. Eur Rev Med Pharmacol Sci. 2017;21(19):4386-4390.

11. Zhang M, Bai L, Kang J, Ge J, Peng W. Links between arterial stiffness and bone mineral density in middle-aged and elderly Chinese individuals: A cross-sectional study. BMJ Open. 2019;9(8):e029946. doi:10.1136/bmjopen-2019-029946

12. Makovey J, Chen JS, Hayward C, Williams FMK, Sambrook PN. Association between serum cholesterol and bone mineral density. Bone. 2009;44(2):208-213. doi:10.1016/j.bone.2008.09.020

13. Wang Y, Dai J, Zhong W, Hu C, Lu S, Chai Y. Association between serum cholesterol level and osteoporotic fractures. Front Endocrinol (Lausanne). 2018;9:30. doi:10.3389/fendo.2018.00030

14. Zhou Y, Deng T, Zhang H, et al. Hypercholesterolaemia increases the risk of high-turnover osteoporosis in men. Mol Med Rep. 2019; 19(6):4603-4612. doi:10.3892/mmr.2019.10131

15. You L, Sheng Z, Tang C, Chen L, Pan L, Chen J. High cholesterol diet increases osteoporosis risk via inhibiting bone formation in rats. Acta Pharmacol Sin. 2011;32(12):1498-1504. doi:10.1038/aps.2011.135

16. An T, Hao J, Sun S, et al. Efficacy of statins for osteoporosis: A systematic review and meta-analysis. Osteoporos Int. 2017;28(1):47-57. doi:10.1007/s00198-016-3844-8

17. Qaseem A, Forciea MA, McLean RM, Denberg TD; Clinical Guidelines Committee of the American College of Physicians. Treatment of low bone density or osteoporosis to prevent fractures in men and women: A clinical practice guideline update from the American College of Physicians. Ann Intern Med. 2017;166(11):818. doi:10.7326/ M15-1361 
18. Yang YL, Xiang ZJ, Yang JH, Wang WJ, Xiang RL. The incidence and relative risk of adverse events in patients treated with bisphosphonate therapy for breast cancer: A systematic review and meta-analysis. Ther Adv Med Oncol. 2019;11:1758835919855235. doi:10.1177/175883 5919855235

19. Gupta T, Das N, Imran S. The prevention and therapy of osteoporosis: A review on emerging trends from hormonal therapy to synthetic drugs to plant-based bioactives. J Diet Suppl. 2019;16(6):699-713. doi:10.1080/19390211.2018.1472715

20. He J, Li X, Wang Z, et al. Therapeutic anabolic and anticatabolic benefits of natural Chinese medicines for the treatment of osteoporosis. Front Pharmacol. 2019;10:1344. doi:10.3389/fphar.2019.01344

21. Tiptiri-Kourpeti A, Fitsiou E, Spyridopoulou K, et al. Evaluation of antioxidant and antiproliferative properties of Cornus mas L. fruit juice. Antioxidants (Basel). 2019;8(9):377. doi:10.3390/antiox8090377

22. Sozański T, Kucharska AZ, Szumny A, et al. The protective effect of the Cornus mas fruits (cornelian cherry) on hypertriglyceridemia and atherosclerosis through PPARa activation in hypercholesterolemic rabbits. Phytomedicine. 2014;21(13):1774-1784. doi:10.1016/j.phymed. 2014.09.005

23. Sozański T, Kucharska AZ, Rapak A, et al. Iridoid-loganic acid versus anthocyanins from the Cornus mas fruits (cornelian cherry): Common and different effects on diet-induced atherosclerosis, PPARs expression and inflammation. Atherosclerosis. 2016;254:151-160. doi:10.1016/j.atherosclerosis.2016.10.001

24. Sozański T, Kucharska AZ, Szumny D, et al. Cornelian cherry consumption increases the I-arginine/ADMA ratio, lowers ADMA and SDMA levels in the plasma, and enhances the aorta glutathione level in rabbits fed a high-cholesterol diet. J Funct Foods. 2017;34:189-196. doi:10.1016/j.jff.2017.04.028

25. Sozański T, Kucharska AZ, Wiśniewski J, et al. The iridoid loganic acid and anthocyanins from the cornelian cherry (Cornus mas L.) fruit increase the plasma I-arginine/ADMA ratio and decrease levels of ADMA in rabbits fed a high-cholesterol diet. Phytomedicine. 2019;52:1-11. doi:10.1016/J.PHYMED.2018.09.175

26. Sozański, T, Kucharska, AZ, Szumny, A, et al. The protective effect of the Cornus mas fruits (cornelian cherry) on hypertriglyceridemia and atherosclerosis through PPARa activation in hypercholesterolemic rabbits. Phytomedicine. 2014;21(13):1774-1784.

27. Gholamrezayi A, Aryaeian N, Rimaz S, et al. The effect of Cornus mas fruit extract consumption on lipid profile, glycemic indices, and leptin in postmenopausal women: A randomized clinical trial. Phyther Res. 2019;33(11):2979-2988. doi:10.1002/ptr.6476

28. Kucharska AZ, Szumny A, Sokól-Letowska A, Piórecki N, Klymenko SV. Iridoids and anthocyanins in cornelian cherry (Cornus mas L.) cultivars. J Food Compos Anal. 2015;40:95-102. doi:10.1016/j.jfca.2014.12.016
29. Sozański T, Kucharska AZ, Wiśniewski J, et al. The iridoid loganic acid and anthocyanins from the cornelian cherry (Cornus mas L.) fruit increase the plasma L-arginine/ADMA ratio and decrease levels of ADMA in rabbits fed a high-cholesterol diet. Phytomedicine. 2019; 52:1-11. doi:10.1016/j.phymed.2018.09.175

30. Kucharska A, Sokół-Łętowska A, Oszmiański J, Piórecki N, Fecka I. Iridoids, phenolic compounds and antioxidant activity of edible honeysuckle berries (Lonicera caerulea var. kamtschatica Sevast). Molecules. 2017;22(3):405. doi:10.3390/molecules22030405

31. Campbell GM, Sophocleous A. Quantitative analysis of bone and soft tissue by micro-computed tomography: Applications to ex vivo and in vivo studies. Bonekey Rep. 2014;3:564. doi:10.1038/bonekey.2014.59

32. Verdelis K, Lukashova L, Atti E, et al. MicroCT morphometry analysis of mouse cancellous bone: Intra- and inter-system reproducibility. Bone. 2011;49(3):580-589. doi:10.1038/jid.2014.371

33. Nowak B, Matuszewska A, Szandruk M, et al. Effect of long-term administration of mangiferin from Belamcanda chinensis on bone metabolism in ovariectomized rats. J Funct Foods. 2018;46:12-18. doi:10.1016/j.jff.2018.04.048

34. Komori T. Animal models for osteoporosis. Eur J Pharmacol. 2015;759: 287-294. doi:10.1016/j.ejphar.2015.03.028

35. Moshiri A, Sharifi AM, Oryan A. Role of simvastatin on fracture healing and osteoporosis: A systematic review on in vivo investigations. Clin Exp Pharmacol Physiol. 2016;43(7):659-684. doi:10.1111/14401681.12577

36. Kim AR, Kim J-H, Kim A, et al. Simvastatin attenuates tibial bone loss in rats with type 1 diabetes and periodontitis. J TransI Med. 2018;16. doi:10.1186/S12967-018-1681-6

37. Yang CN, Kok SH, Wang HW, et al. Simvastatin alleviates bone resorption in apical periodontitis possibly by inhibition of mitophagy-related osteoblast apoptosis. Int Endod J. 2019;52(5):676-688. doi:10.1111/ iej.13055

38. Oryan A, Kamali A, Moshiri A. Potential mechanisms and applications of statins on osteogenesis: Current modalities, conflicts and future directions. J Control Release. 2015;215:12-24. doi:10.1016/j.jconrel. 2015.07.022

39. Shahrezaee M, Oryan A, Bastami F, Hosseinpour S, Shahrezaee MH, Kamali A. Comparative impact of systemic delivery of atorvastatin, simvastatin, and lovastatin on bone mineral density of the ovariectomized rats. Endocrine. 2018;60(1):138-150. doi:10.1007/s12020-0181531-6

40. Fan J, Kitajima S, Watanabe T, et al. Rabbit models for the study of human atherosclerosis: From pathophysiological mechanisms to translational medicine. Pharmacol Ther. 2015;146:104-119. doi:10. 1016/j.pharmthera.2014.09.009 